


\title{
La moral del juguete de Baudelaire y las maneras estético-sagradas de la mirada
}

\author{
Baudelaire's The Philosophy of Toys and the Aesthetic-Sacred \\ Forms of Gaze
}

Francisco Márquez Osuna

Posgrado en Filosofía

Universidad Nacional Autónoma de México

\begin{abstract}
RESUMEN: Este artículo trabaja, a partir de una lectura del ensayo La moral del juguete de Charles Baudelaire, las tres maneras estético-sagradas que recorre la mirada. Estas tres maneras son: la manera idólatra que "adora" la imagen y restringe la mirada del observador a la pura opticidad; la manera iconoclasta que prohíbe y condena la imagen debido al "poder" que ésta puede evocar en el observador; y la manera apofática que "abre" la imagen al núcleo inefable de lo invisible, lugar al cual es arrastrado el observador por el poder propio de la imagen. Estas tres maneras transitan el camino que va de la era de la imagen a la era del arte.
\end{abstract}

Abstract: By analyzing Charles Baudelaire's essay The Philosophy of Toys this paper discusses the three aesthetic-sacred forms by which the gaze skims. The first refers to the idolatrous form that worships the image and which restricts the observer's gaze to pure opticality. The second is the iconoclastic form that forbids and condemns the image, due to the power that it may invoke in the observer. Finally, there is the apophatic form that "opens" the image to the ineffable core of the invisible, place where the observer is dragged to by the power of the image. These three forms travel the way that goes from the Image Age to the Art Age.

Palabras clave: Charles Baudelaire, estética idólatra, estética iconoclasta, estética apofática, economías de la visión.

KEYwords: Charles Baudelaire, Idolatrous aesthetics, Iconoclastic aesthetics, Apophatic aesthetics, visual economies.

RECIBIDO: 14 de octubre de 2016 • AcEPTADO: 10 de noviembre de 2016 

Francisco Márquez Osuna

Posgrado en Filosofía

Universidad Nacional Autónoma de México

\section{La moral del juguete de Baudelaire y las maneras estético-sagradas de la mirada}

... cada hombre tiene una imagen por la que renunciaría al mundo, ¿cuántos no la buscarían en una vieja caja de juguetes?

WaLter Benjamin, Juguetes y juego.

En las obras completas de Charles Baudelaire editadas actualmente por Gallimard, el autor del Spleen de París escribe un breve pero fascinante ensayo titulado "Morale du joujou" (Baudelaire 1975: 581-587). Este texto, publicado originalmente en 1853 en Le Monde littéraire, menciona lo siguiente:

Todos los niños hablan a sus juguetes; los juguetes se convierten en actores en el gran drama de la vida [...] Los niños revelan con sus juegos su gran facultad de abstracción y su elevado poder imaginativo. [...] Esta facilidad para contentar su imaginación manifiesta la espiritualidad de la infancia en sus concepciones artísticas. El juguete es la primera iniciación del niño al arte, o, mejor dicho, es para él la primera realización artística y, una vez llegada la madurez, las realizaciones perfeccionadas no darán a su espíritu el mismo calor, ni los mismos entusiasmos, ni la misma creencia (Baudelaire 2014: 45 y 48. Las cursivas son mías).

Baudelaire observa que, si en verdad existe una dimensión sagrada en lo humano, ésta se manifiesta desde la niñez. Interroga, así, por el 
sentido de lo sagrado en la vida infantil, como si una obsesión por el origen de lo sagrado se apoderara de su palpitante pluma. Y si profundiza en la espiritualidad de los niños es para indagar la relación intrínseca de lo sagrado en las artes, pues en ellas parece sobrevivir el pathos latente de los tiempos perdidos: el tiempo de la infancia y el tiempo del pasado cultural. Ante este semblante, ¿qué genealogías de la espiritualidad hacen viables las artes? Y, de esta forma, ¿cómo las artes expresan lo sagrado?

Ahora bien, la manera en que las artes hacen posible la visión de lo sagrado desgarra la imagen. Ante esta violencia, aquello que (nos) mira en la obra de arte se esconde, porque el elemento sagrado en las artes - como en los juguetes - es escurridizo, se oculta y escapa. Al fugarse, la imagen disuelve su presencia y queda abierta ante la ausencia; es decir, ante una apertura que muestra una herida en la imagen. En este sentido menciona Didi-Huberman lo siguiente:

Cuando un niño pequeño al que se ha dejado solo observa ante él los pocos objetos que pueblan su soledad - por ejemplo una muñeca, una bobina, un cubo o simplemente la sábana de su cama-, ¿qué ve exactamente o, mejor, cómo ve? [...] Lo imagino en la expectativa: ve en el entorpecimiento de esperar, sobre el fondo de la ausencia materna. Hasta el momento en que lo que ve se abra de improviso, alcanzado por algo que, en el fondo - o desde el fondo, me refiero a ese mismo fondo de ausencia-, lo hiende, lo mira. Algo de lo cual, finalmente, hará una imagen. La imagen más simple, sin duda: pura acometida, pura herida visual (Didi-Huberman 2014: 49).

Lo que mira al niño, al igual que al observador de imágenes artísticas, es lo sagrado que se refugia en la exterioridad de los materiales burdos que hacen posibles las obras plásticas. Por ejemplo, en David Hammons, el refugio queda expuesto a través del desgarramiento de lo material para vislumbrar - o presentar - los colores interiores de lo sagrado que se derraman.

Así, pues, el problema del arte desde Baudelaire, a través del ensayo de La moral del juguete, resulta nuclear para comprender cómo acontece lo espiritual y lo sagrado en el arte contemporáneo. Con Baudelaire surgen las preguntas: ¿cómo se visualiza la interioridad en la exteriori- 


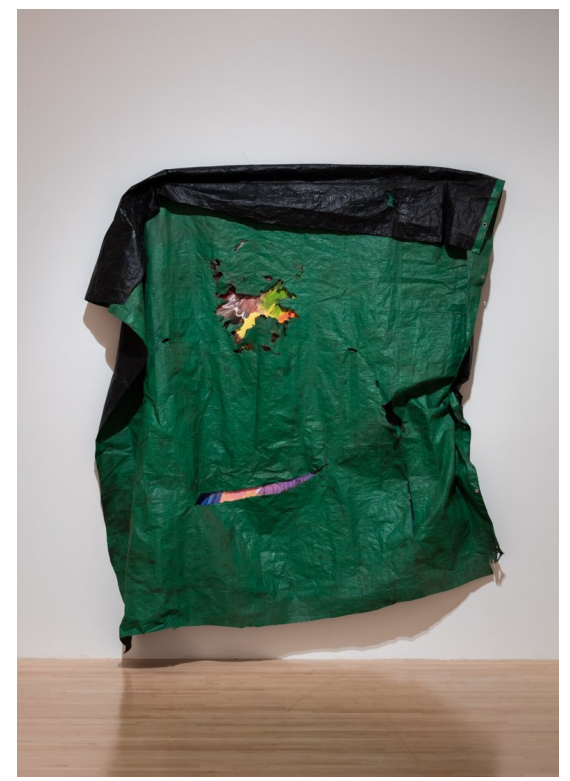

Imagen 1. David Hammons (2010). Untitled. Acrílico sobre lienzo y lona.

Los Ángeles, MOCA. Fotografía: Francisco Márquez Osuna

dad material?, ¿qué tendencias estéticas modulan la visión para desgarrar la imagen?, ¿qué es necesario hacer para que la imagen finalmente nos mire desde su interior, desde su herida?

En la postura que mantiene Baudelaire subyace una "economía de la imagen" que recorre la vida del observador - o acaso sujeto- que está delante de imágenes. Por "economía de la imagen" debe entenderse una forma peculiar de disposición de la imaginación que permite estar ante las imágenes (Mondzain 2005: 13) ${ }^{1}$ - ante aquello que nos mira

1 Mondzain indaga en la polivalencia de la palabra de Oikonomia (donde uno de sus múltiples sentidos es la traducción al latín como Dipositio) que fue de vital importancia en el desarrollo político y teológico de las disputas del Icono en Bizancio. Mondzain observa que el concepto de Oikonomia era el elemento central para afirmar la pertinencia de los iconos, pues los iconódulos sostenían que gracias a la economía (como disposición) existía traslado de lo visible y de lo invisible, de lo profano y lo sagrado, de la realidad intangible a la realidad empírica, etc. La economía transfiere o funciona como intermedio entre dos realidades, es decir, la humana y la divina (Mondzain 2005: 11-66). Por ello, para la autora, la economía de la imagen sagrada "tiene que ver con un organismo o una disposición interna cuya visibilidad se hace accesible a nosotros" (2005: 21). De esta manera, el concepto de economía 
en la imagen - . Para Jean-Luc Nancy, lo que mira en la pintura - en específico en los retratos - es un "cara a cara" o un egon que desafía lo visual: "No puedo mirar sin que eso me mire, me incumba [me regarde]. Lo que el retrato presenta es siempre esa guarda de sí; y junto con ella, esto: de qué manera el sí se guarda porque se extravía" (2012: 74. Las cursivas son mías). Pero ¿qué "guarda" la imagen sino la presencia de una inefabilidad inscrita en la materia, es decir, de lo sagrado en la interioridad de la mirada?

La "economía de la imagen" en La moral del juguete revela una disposición del niño para mirar el alma y, al mismo tiempo, el deseo de ser mirados por esos objetos imaginarios-imaginantes. Se podría decir, como Marie-José Mondzain, que aquí se juega un intercambio escópico - el deseo de mirar y de ser mirado- que, según esta autora, es una disposición corporal ante lo sagrado:

where the body only allows Itself to be seen gloriously and miraculously. There is no more contact between the divine prototype and its icon than between the icon and its human model. In any case, what is called the incarnation is neither an immersion in the flesh nor an idealization of matter, but rather something like the gaze's imitation of itself when it is haunted by the desire to be seen. To become flesh is here nothing other than the obtaining of a certain gaze in the empty space where he who accedes to existence when he enters the field of what constitutes him for the gaze of another is incarnated. Being in possession of the existence of his flesh only by virtue of the sole fact of another gaze requires that that gaze be endowed with an infinite thirst for imagining. Such is the thirst of God, a pure image given to the thirst of the humans whom he consigns to his imitation. The imaginal relation gives birth to the flesh of being. The symbol is, strictly speaking, imaginary $(2005: 177){ }^{2}$

se entiende aquí como un espacio "intermedio" entre la imagen que se observa y la manera en la que el observador puede componer una relación con la imagen; así en este artículo se observan tres disposiciones o economías ante la imagen: la idólatra, la iconoclasta y la apofática.

2 ... donde el cuerpo sólo se deja ver de manera gloriosa y milagrosa. No hay más contacto entre el prototipo divino y su icono que entre el icono y su modelo humano. En cualquier caso, lo que se llama "encarnación" no es ni una inmersión en la carne ni una idealización de la materia, sino que es, más bien, una especie de imitación que la propia mirada realiza cuando está hechizada por el deseo de ser 
El juguete es el símbolo o primer imaginario ante el que se enfrenta el niño. Del infante depende hacer del juguete ya sea un ídolo que lucha entre ser adorado o destruido, o un rostro vestigial (Nancy 2012: 78) ${ }^{3}$ en tanto centro significante abierto al abismo y vestigio que se borra en el tiempo.

¿Cómo afecta al desarrollo posterior de los niños esta relación imaginal que es suscitada ante los "ojos" del juguete? Baudelaire escribe lo siguiente:

Creo que en general los niños actúan sobre sus juguetes [...], su elección está dirigida por disposiciones y deseos, vagos, es cierto, no formulados, pero muy reales. No obstante, no me atrevería a afirmar que lo contrario no suceda, es decir, que los juguetes actúan sobre el niño, sobre todo en el caso de la predestinación artística o literaria (2014: 51-52).

¿Hasta qué punto es en la niñez donde la creencia cobra su verdadera vivacidad? También, ¿en qué medida es en la niñez donde la visión - esa técnica de nuestros cuerpos que idealiza la materia-, todavía no educada, desea mirar el alma de lo sagrado, en este caso desde los juguetes?

La mirada, ante este panorama, se vislumbra en una "economía de la imagen" que es, a la vez, estética y sagrada. ¿Bajo qué criterios el arte y los juegos de los niños - dicho de otra forma, lo lúdico - atraviesan por los mismos senderos de lo sagrado que la religión? Una respuesta tentativa radica en que por lo estético y lo sagrado se juega toda relación ante lo otro. Finalmente, esta economía enfrenta a la imagen desde tres

mirada. Devenir carne no es aquí otra cosa que la obtención de una cierta mirada en el espacio vacío donde aquel que accede a la existencia se encarna cuando entra en el campo de aquello que lo constituye para la mirada del otro. Estar en posesión de la existencia de la propia carne por el solo hecho de la mirada del otro requiere que esta mirada esté dotada con una infinita sed de imaginar. Esta es la sed de Dios, imagen pura ofrecida a la sed de los hombres, a los que él entrega a su imitación. La relación imaginal da a luz a la carne del ser. El símbolo es, estrictamente hablando, imaginario. (La traducción es mía).

3 "[Los rostros vestigiales] ya no tienen abertura en su centro y son ellas mismas lo abierto del cuadro [o para nuestro caso de la imagen]". De esta manera un Icono es, justamente, un rostro vestigial, pues su verdad es una presencia que se ausenta, una inefabilidad inscrita en la materia. 
maneras de mirar que se contraponen entre sí: la manera idólatra, que conserva la imagen, pero no ve su mirada; la iconoclasta, que destruye la imagen porque teme su mirada; y la apofática, que abre la imagen ante el vacío y, desde ahí, en su inefabilidad, nos mira. A continuación se explican estas tres maneras o tendencias, según se observan al final del ensayo de Baudelaire.

\section{La manera idólatra}

Esta "economía de la imagen" se explica a partir de una frase muy escuchada en el mundo infantil. Con un ejercicio de memoria quizá el lector podrá escuchar el resonar de la siguiente terrible sentencia: ante una situación cotidiana en la vida de los niños, cuando un niño se presentaba con un juguete nuevo, reluciente, brillante, colorido, imponente como un coloso a pesar de su diminuto tamaño, los compañeros de juego pedían tocar ese objeto; entonces el poseedor del juguete sentenciaba: "puedes ver, pero no tocar". Este privilegio de la visión sobre la manipulación táctil muestra la lógica del funcionamiento de la manera idólatra de la mirada.

Entonces, ¿a qué remite esta economía de la visión? La manera idólatra remite a la pura opticidad del objeto, pero restringe el poder háptico (Riegl 1992: 38-74; Deleuze 2007: 199-236) del juguete. ${ }^{4}$ La mirada idólatra crea un espacio insalvable de lejanía entre el niño que desea "más que mirar el juguete" y el juguete mismo, por ello, las "superficies" táctiles quedan ajenas a la mirada idólatra. Es decir, la idolatría impide la relación del tacto que abre la disposición del objeto para la mirada y una relación personal con dicho objeto. Restringido a la dis-

4 Desde la teoría perceptiva de la imagen según Alois Riegl (1992) se observan dos regímenes visuales, uno de lejanía y otro de cercanía (Riegl 1992: 38), al régimen de lejanía se le nombra como espacio óptico y al de cercanía como espacio háptico. El espacio óptico, entonces, tiende a alejar el objeto del observador, de tal forma que la visión "ve" en perspectiva; por otra parte, en el espacio háptico existe una proximidad entre el objeto y el observador donde el ojo "deviene" en tacto, la visión aquí no ve en perspectiva, más de forma plana. Gilles Deleuze comentando a Riegl dirá lo siguiente: "Es extraño, pero literalmente es un ojo que se comporta como tacto. Es un ojo táctil. (...) Es el ojo como tal el que se comporta como un tacto" (Deleuze 2007: 204). 
tancia óptica, el niño que no posee el juguete, prescinde del contacto con un objeto que convoca a un "más que a mirar".

Baudelaire explica esta tendencia de adoración de los juguetes de la siguiente forma: "Hay niños [que adoran sus juguetes]: no utilizan sus juguetes, los economizan, los ponen en orden, hacen con ellos bibliotecas y museos, y los muestran de vez en cuando a sus amiguitos rogándoles que no los toquen. Yo desconfiaría instintivamente de esos niños-hombres" (2014:56).

La desconfianza de Baudelaire hacia estos niños radica en el temor que el cristianismo ha desatado en torno al problema que relaciona al ídolo y al ícono. En efecto, las disputas bizantinas en torno a las imágenes no han dejado de reaparecer una y otra vez en el imaginario cristiano y occidental. En las disputas iconoclastas del cristianismo bizantino, el problema de la imagen indagaba en la distinción teológica entre veneración (proskynêsis) y adoración (latreia) (Schönborn 1998: 148 y 198; Freedberg 1991: 393). Juan Damasceno explica esta distinción de la siguiente forma: aquel que venera la imagen distingue entre el soporte representativo y lo representado, y quien adora la imagen confunde el soporte con lo representado (Otero 2012: 12). Por medio de esta distinción bizantina, la manera idólatra es conservadora porque el núcleo de atención de la mirada del idólatra deviene en adoración, esto es, se confunde el signo con el símbolo.

Con la idolatría, el poder sagrado de la imagen se restringe al sujeto que ostenta el dominio del objeto. Al idólatra le preocupa que el poder de la imagen se gaste ante la manipulación, también le inquieta que el ídolo se manche o se altere: el idólatra busca mantener una pureza radical de la mirada frente a la impureza del tacto. Sin embargo, ante la adoración idólatra, ¿es posible que la imagen devuelva una mirada?, ¿no se pierde el poder de la imagen cuando la representación no corresponde a lo invisible o al aura de los objetos? Con estas dos preguntas que quedan abiertas, se atenderá la segunda manera lúdico-religiosa que nos presenta Charles Baudelaire en su ensayo sobre los juguetes.

\section{La manera iconoclasta}

Si la idolatría conserva la imagen, la tendencia iconoclasta la destruye o, en el mejor de los casos, la ignora. En esta segunda manera de 
enfrentarse a los objetos visuales se presenta la imposibilidad de comprender un fenómeno invisible dentro de lo visible. La tendencia iconoclasta niega la posibilidad de pensar que la imagen sea algo más que una imagen, por ello, no puede ser ni símbolo, ni síntoma del tiempo (Didi-Huberman 2013: 274-275 y 389). La tendencia iconoclasta borra - o, mejor dicho, pretende borrar - toda relación entre el sujeto y la imagen. La tendencia iconoclasta, como afirma Freedberg, es un problema de represión porque se teme el poder de la imagen (1994: 11). Por eso, a pesar de que aparenta ser una postura contraria a la idolatría, es, no obstante, complementaria; justamente porque el tema vuelve a ser la adoración de la imagen. El problema de la iconoclasia tiene como fundamento la destrucción de la imagen porque no deben adorarse los objetos materiales o visuales. Pero, ¿por qué no deben adorarse? Porque las imágenes por sí mismas - pensarían los iconoclastas - no ejercen ningún poder; quien adora una imagen cae en la superstición. Esta tendencia en los niños, Baudelaire la describirá de la siguiente forma:

Hay [niños] que rompen enseguida el juguete apenas lo han puesto en sus manos, apenas lo han examinado; y en cuanto a éstos [niños], confieso que ignoro el sentimiento misterioso que les hace actuar. ¿Son presa de una cólera supersticiosa contra esos menudos objetos que imitan a la humanidad, o bien les hacen pasar una especie de prueba masónica antes de introducirlos en la vida infantil? -Puzzling question! (2014: 57).

Para la economía iconoclasta, la imagen no dispone de ninguna apertura sagrada. Para esta postura, la imagen no es sagrada porque es imposible que la materia inanimada "nos mire". Para los iconoclastas, las imágenes son objetos cerrados, pura materialidad, como si los materiales no expresaran lo sagrado.

Aunque hay que subrayar que la tendencia iconoclasta ha jugado un papel predominante en la construcción del mundo del arte en la modernidad. Hans Belting, en su monumental obra titulada Imagen y culto, describe el paso de la era de la imagen a la era del arte. Según Belting, tras la Reforma de Martín Lutero, se transforma la función de la imagen medieval - de hecho deja de ser imagen para transformarse en arte-. Dicha transformación consiste en la pérdida de peligro de las imágenes, 
es decir, del riesgo de caer en la idolatría. Desde la época de Lutero, adorar estatuillas o telas será propio de iletrados, no de hombres cultivados en la verdad; la modernidad de la Reforma luterana consiste en desacralizar la imagen. Esta es una extraña iconoclasia que no destruye la representación, sino la función religiosa de la imagen. Así, pues, las imágenes desde la época de la Reforma - o desde la era de la invención del arte - pasan a un nuevo espacio que está lejano del templo y, por tanto, alejado de lo sagrado. En palabras de Belting:

Según Lutero, [las imágenes] [...] deben perder su función. Al fin y al cabo, lo que el observador hace con la imagen [para Lutero,] es cosa suya, no de la propia imagen. [...] En las colecciones de arte las imágenes que habían perdido su función en las iglesias adquieren nuevas funciones en la representación del arte [...] separa una concepción antigua de la imagen de una nueva. [...] En el ámbito católico no hubo condena de las imágenes que eran objeto de veneración, pero a pesar de ello, tampoco se pudo frenar la metamorfosis hacia la obra de arte (2009: $607 \mathrm{y} \mathrm{ss).}$

La disposición del poder de la imagen se ve modificada en toda la cristiandad, pues incluso el catolicismo transformará su manera de observar: el observador moderno ya no es el mismo que el participante de los ritos litúrgicos. Por ello,

la iconoclastia [moderna] inauguró un cambio [...] fundamental en la balanza del poder - de la imagen a la palabra. El protestantismo materializó el lenguaje como el medio de comunicación entre el hombre y Dios, y así, en lugar de las imágenes pintadas de las iglesias, se colocaron los textos de la biblia [que prohíben las imágenes] (Camille 2000: 364).

Las transformaciones tecnológicas acontecidas en el siglo XVI cambiaron la disposición de la mirada occidental: la imagen, finalmente, dejó de ser el soporte cognitivo - y con ello se transforma la función de la cultura visual - , y se cambió por uno que privilegia la escucha y la palabra escrita. En este sentido, Lutero afirma que: "El reino de Dios es un reino de la escucha, no un reino de la vista. (...) La palabra de Dios entendida correctamente es la base de la fe, quien la tiene pura y sin falsificar, puede triunfar en el combate contra todas las puertas del infierno" (Martín Lu- 
tero, citado en Belting 2009: 616). Ante la cita anterior, las palabras de Walter Benjamin resultan muy atinadas cuando comenta: "En los largos períodos históricos, junto con las modalidades generales de existencia de las colectividades humanas, cambian también los modos de percepción. La manera en que opera la percepción, el medio en el que se produce, dependen no sólo de la naturaleza humana sino de los condicionamientos históricos" (2015: 17). ¿Cómo mirar una imagen que ha abandonado - o que ha sido abandonada por - el culto para instalarse en el museo?, ¿cómo puede esta imagen mirar(nos) al cambiar de espacio?, ¿cómo logra la imagen sobrevivir ante esta profanación, ante este desencantamiento?

En la época de la Reforma, la imagen se seculariza - sin importar el lugar de la cristiandad en que se encuentre-; el valor del museo, de la galería o de las colecciones de pinturas, gana terreno sobre el poder de la imagen de culto. También la reforma calvinista supuso una disputa ante el poder de la imagen, según Alain Besançon:

Lo que cambia con Calvino no es la idea de Dios, sino la idea del mundo. Éste se des-diviniza. Antes incluso de que se plantee la cuestión de las imágenes, no es posible ver de antemano cómo un elemento del mundo creado que no fuera el alma humana, que conoce a Dios por 'viva experiencia', podría servir de soporte a una imagen divina (2003: 235).

El mundo del arte que se inaugura en la modernidad es, por principio, iconoclasta; así que no es de extrañar que con el tiempo se pierda el aura del arte (Benjamin 2015: 9-34). ${ }^{5}$ En la nota 8 del ensayo La obra de arte en la época de su reproducción mecánica, Benjamin afirma que "a medida que la imagen cultual se seculariza, la noción de unicidad se torna más difusa. [...] Con la secularización del arte, la autenticidad va

5 El concepto de aura le sirve a W. Benjamin para hacer notar una disposición distinta ante los objetos en la era de "reproductibilidad mecánica" y la "tradición" (Benjamin 2015: 16). La transferencia que existe entre el objeto y el observador se ve modificada porque el aura se pierde al existir la posibilidad de copiar la obra o de reproducirla en un espacio que no le es propio, por ejemplo, existe una diferencia entre escuchar música en el tráfico y escucharla en una sala de conciertos. Por otra parte, el aura comienza a desgastarse primero con la pérdida de sacralidad de la imagen, después con la facilidad para reproducirla mecánicamente, ante esta situación "recuperar" el aura de los objetos implica desarrollar una nueva economía o disposición tanto del objeto como del observador contemporáneo. 
sustituyendo el valor cultual" (2015: 21, nota 8). No obstante, en la obra de arte sobrevive una tendencia que evita pensar las imágenes como un objeto meramente profano:

El espíritu calvinista, al tiempo que impone la iconoclasia, deja que la luz icónica bañe las imágenes seculares, que tolera, o más bien autoriza, debido a su preocupación por dejar que se extienda y se cumpla el trabajo del hombre, santificando y ejerciéndose "solamente para gloria de Dios". [...] Por lo tanto, lo divino en la obra ya no procede de lo representado, sino de quien representa: el artista. [...] [Calvino] abre una puerta a la divinización del artista. Inesperadamente, la luz sobrenatural sigue brillando sobre el arte desacralizado y alimenta una idolatría distinta de la que Calvino habría querido arrancar de cuajo, pero que le hubiera horrorizado aún más (Besançon 2003: 238 y ss.).

Por supuesto, iconoclasia e idolatría se complementan como dos caras de una moneda, ambas desean atentar contra el aura de la imagen. No obstante, la luz icónica de las imágenes (nos) sigue mirando; un semblante interno de la imagen se niega a perecer y sobrevive aún en el arte moderno. Disfrazado de síntoma, el símbolo late en la era del arte, justamente porque la supervivencia $-\mathrm{y}$ la memoria - trabaja en los símbolos; es decir, como una plasticidad oscilatoria y pulsante del tiempo: del presente y del pasado (tiempo histórico y tiempo mítico). "El símbolo, en suma, no revela su propia fuerza y su genealogía - su complejidad temporal, su espesor de supervivencias, su anclaje corporal- más que retornando, en la historia, como síntoma" (Didi-Huberman 2013: 389).

Pero, ¿cómo puede el observador contemporáneo adentrarse en el aura de la imagen, en la mirada de la imagen? Para poder penetrar en lo simbólico latente de la imagen, es necesario plantear una tercera economía. Siguiendo la teoría de Baudelaire, la tercera tendencia puede ser denominada apofática.

\section{La manera apofática}

Si la manera idólatra conserva la imagen y la iconoclasta la destruye, la manera apofática es una disposición de la mirada que abre la imagen, 
pero que - paradójicamente - desdibuja la visión a través del desagarre de lo visual. Se desgarra la frontera que divide lo posible de lo imposible, lo visible de lo invisible, finalmente, la mirada del observador ante la mirada ineluctable - como afirma Didi-Huberman - de la imagen. Para explicar esta última tendencia en la espiritualidad de la niñez, Baudelaire escribe las siguientes palabras:

La mayoría de los críos quieren sobre todo ver el alma [de su juguete], unos al cabo de algún tiempo de ejercicio, otros enseguida. La invasión más o menos rápida de este deseo es lo que determina la longevidad más o menos grande del juguete. No tengo valor para censurar esta manía infantil: es una primera tendencia metafísica. Cuando este deseo se ha metido en la médula cerebral del niño, llena sus dedos y sus uñas de una agilidad y una fuerza singulares. El niño da vueltas y más vueltas a su juguete, lo rasca, lo sacude, lo golpea contra la pared, lo arroja al suelo. De vez en cuando le hace volver a empezar sus movimientos mecánicos, a veces en sentido inverso. La vida maravillosa se detiene. El niño [...] hace un supremo esfuerzo; finalmente lo entreabre, él es el más fuerte. Pero, ¿dónde está el alma? Aquí es donde comienza l'hébétement (aturdimiento, deslumbramiento, entontecimiento) y la tristeza (2014: 56-57).

La materialidad se sitúa como zona intermedia entre la luz y la noche, entre ruido y el silencio, la tristeza de ver cómo lo sagrado se escapa en nuestras manos. La luz de la materialidad por sí misma no es suficiente, pero sin ella toda posibilidad que desprenda un espacio-sagrado luminoso de un espacio-secular sería imposible. La materialidad, por tanto, no es del todo extraña a la vida sagrada, es la zona intermedia necesaria y condicionante del aparecer sagrado (Cirlot 2010: 63-83), ¿cómo podría un espíritu sin carne, realmente ser un espíritu?, ¿cómo sería posible su videncia y su evidencia? La visión se desdibuja, lo visible deviene inefable.

Como imagen abierta, tanto la imagen religiosa como la imagen en la era del arte presentan un interior inaccesible, pues desbordan los medios mismos de la visión. Sin embargo, la imagen no deja de mirar(nos). Es interesante y paradójico que toda mirada de la imagen, que toda aura que emana de la obra de arte, no sea más que una presencia ausente. Así, en palabras de Amador Vega: 
La vía apofática no hace sino afirmar, desde la negación, la realidad invisible de Dios al modo en que lo profano puede revelar la naturaleza de lo sagrado oculta en él. [...] [En] tanto símbolo inconfundible de lo sagrado, el contexto profano se presenta, paradójicamente, como el mejor refugio de aquello que debía ser, precisamente, preservador de lo que no es santo (2005: 30).

Entonces aparece el arte como resguardo último - en su sentido de actual - de lo sagrado, si bien la secularización desterritorializó lo sagrado de la religión, se reterritorializó en el mundo del arte. Pues justamente la naturaleza de lo sagrado es profundamente ambigua:

se manifiesta tanto en la luz como en las tinieblas, nos permite aventurar nuevos caminos para detectar su acción y su pervivencia aun en su aparente ausencia. Pues lo que desaparece con la modernidad [...] no es tanto lo sagrado como su representación religiosa. [...] Pero lo sagrado, gracias a su ausencia determinada de forma, a su modo caótico de ser, puede transformarse y devenir todas las cosas (Vega 2005: 31).

Por ello, Charles Baudelaire observa que cuando el niño penetra en su juguete es cuando logra por fin ver en su interior y la crisis se apodera de él, como lo hace, por otra parte, la imagen que nos mira. Así lo describe Didi-Huberman: "Una imagen en crisis, una imagen que critica la imagen [...] y por eso mismo una imagen que critica nuestras maneras de verla en el momento en que al mirarnos, nos obliga a mirarla verdaderamente. Y a escribir esa misma mirada, no para 'transcribirla' sino ciertamente para construirla” (2014: 113). Pero, ¿qué vemos de la imagen o del alma del juguete si no es su ausencia? La materialidad del objeto, del arte, nos presenta una imagen que se nos ha escapado, un fenómeno destinado a la ausencia, al silencio o a las mutaciones - como John Cage habla de su música - . La presencia de la mirada ante la imagen de arte es la clandestinidad que se escapa. De nuevo, en Didi-Huberman:

Por lo menos una cosa para ver que [la imagen], por más próxima que esté, se repliega en la alta soledad de su forma y, en consecuencia, mediante esta simple fenomenología de la retirada, nos mantiene a dis- 
tancia, nos impone respeto frente a ella. Entonces es cuando nos mira, entonces es cuando permanecemos en el umbral de dos mociones contradictorias: entre "ver" y "perder", entre captar ópticamente la forma y sentir táctilmente - en su presentación misma - que se nos escapa, que sigue destinada a la ausencia (2014: 156).

¿Qué es en definitiva lo que nos mira? Y ¿cómo construir una economía apofática de la imagen que se vacía de sí? La mirada de la imagen no nos regresa un reflejo de nosotros mismos; sería una mirada excesivamente narcisista, idólatra. Más bien, la mirada del arte pictórico es una mirada de la ausencia. Por esta razón, Jean-Luc Nancy menciona:

En la pintura no hay "objeto": nada es "ob-yectado" ante nosotros. En este sentido, el cuadro no está nunca ante nosotros. No está "frente", sino más bien "adelante", en el sentido que yo estoy detrás o dentro del cuadro, en su presencia. [...] El reflejo [del espejo] no tiene lugar más que en presentia, el retrato es in absentia: por esencia, y en todos los sentidos está expuesto a la ausencia (2012: 30).

Finalmente, lo sagrado y lo artístico componen un montaje material de lo imaginario abierto a la mirada de los observadores. Dicho montaje se engarza a través de la tensión existente entre la presencia y la ausencia que transita por las imágenes. Así, en la pintura de David Hammons, la presencia de lo sagrado, dentro de un soporte plástico, es posible por el desgarramiento de una lona; la imagen aquí nos introduce a lo sagrado. Este montaje material de lo imaginario hace presente lo sagrado de dos formas: ópticamente, en tanto que las imágenes son para la vista, y hápticamente, ya que las imágenes manipulan la manera en la que son percibidas. En los niños lo sagrado descansa en el deseo escópico de ver y ser mirados por el alma del juguete, es decir, en la manipulación del juguete hasta quebrarlo: justo ahí — en el destrozo del objeto - subyace la posibilidad de ser mirados. De igual forma, el observador puede aproximarse a la supervivencia de lo sagrado en la imagen cuando se adentra en ella como un niño. Sin embargo, una última advertencia: la presencia de lo sagrado en la imagen es abismal, al mirarla evapora su presencia, enigmáticamente se abre ante lo inefable... lo sagrado - tomando prestadas unas palabras de G. Colli- ama ocultarse (Colli 2009). 


\section{Bibliografía}

Baudelaire, Charles (1975). CEuvres Completes I. París, Gallimard.

- (2014). "Moral del juguete", en Abel Vidal (trad.), Sobre marionetas, juguetes y muñecas. Barcelona, José J. de Olañeta.

Belting, Hans (2009). Imagen y culto. Madrid, Akal.

Benjamin, Walter (2015). La obra de arte en la época de su reproducción mecánica. Madrid, Casimiro Libros.

BesAnçOn, Alain (2003). La imagen prohibida. Madrid, Siruela.

CAMILle, Michael (2000). El ídolo gótico: ideología y creación de imágenes en el arte medieval. Madrid, Akal.

Cirlot, Victoria (2010). La visión abierta: del mito del Grial al surrealismo. Madrid, Siruela.

Colli, Giorgio (2009). La naturaleza ama esconderse. México, Conaculta/ Sexto Piso.

Deleuze, Gilles (2007). Pintura: El concepto de diagrama. Buenos Aires, Cactus.

Didi-Huberman, Georges (2013). La imagen superviviente: Historia del arte y tiempo de los fantasmas según Aby Warburg. Madrid, Abada.

- (2014). Lo que vemos, lo que nos mira. Buenos Aires, Manantial.

Freedberg, David (1991). The Power of Images. Chicago: The University of Chicago.

Mondzain, Marie-José (2005). Image, Icon, Economy: The Byzantine Origins of the Contemporary Imaginary. Stanford, Stanford University Press.

NANCY, Jean-Luc (2012). La mirada del retrato. Buenos Aires, Amorrortu.

Otero, Carlos (2012). "La imagen como paradoja", en Carlos A. Otero (ed.), Iconoclastia: La ambivalencia de la mirada. Madrid, La Oficina de Arte y Ediciones.

RIEGL, Alois (1992). El Arte industrial tardorromano. Madrid, Visor.

SchönBorn, Christoph (1994). God's Human face: The Christ-Icon. San Francisco, Ignatius.

VEGA, Amador (2005). Arte y santidad: Cuatro lecciones de estética apofática. Pamplona, Universidad Pública de Navarra. 